\title{
Saudi Medical Students' Interest in Basic Medical Sciences and the Factors Affecting It
}

\author{
Suha Althubaiti ${ }^{1} \&$ Norah Althubaiti ${ }^{2}$ \\ ${ }^{1}$ School of Medicine, Department of Basic Medical Science, King Saud bin Abdulaziz University for Health \\ Sciences, Riyadh, Saudi Arabia \\ ${ }^{2}$ College of Medicine, King Abdulaziz University, Jeddah, Saudi Arabia \\ Correspondence: Suha Althubaiti, School of Medicine, Department of Basic Medical Science, King Saud bin \\ Abdulaziz University for Health Sciences, Riyadh, Saudi Arabia.
}

Received: January 13, 2018 Accepted: February 19, 2018 Online Published: February 28, 2018

doi:10.5539/gjhs.v10n4p30 URL: https://doi.org/10.5539/gjhs.v10n4p30

\begin{abstract}
Objectives: To evaluate medical students' interest in basic sciences and identify perceived obstacles for choosing a career in basic science.
\end{abstract}

Methods: A cross-sectional survey study was conducted and carried out between March and May 2016 with 600 undergraduate medical students at the College of Medicine, King Saud bin Abdulaziz University for Health Sciences, Riyadh, Saudi Arabia. Students' interest towards basic medical sciences was evaluated using a questionnaire.

Results: A total of 352 medical students (180 male and 172 female) responded. The leading reasons for not pursuing a career in basic sciences were that medical students aimed primarily to become clinicians $(71.6 \%)$, would prefer to engage in clinical research $(40.4 \%)$, were concerned about salaries in basic sciences $(36.6 \%)$, and had not experienced exciting practical training in basic sciences $(26.2 \%)$.

Conclusion: Integrating basic sciences and clinical medicine and increasing research participation will result in more positive attitudes towards basic sciences. Furthermore, reducing the students' concerns will encourage medical students to engage more with basic medical science.

Keywords: medical students, basic sciences, problem based learning curriculum

\section{Introduction}

Basic Medical Sciences (BMS) are the core foundation of good clinical medical practice and important components of any medical curriculum (Patel, Evans, \& Groen, 1989; Patel, Evans, \& Kaufman, 1990). However, the method by which BMS are taught to medical students is of equal importance (Kaufman \& Mann, 1997; Dahle, Brynhildsen, Behrbohm Fallsberg, Rundquist, \& Hammar, 2002). In conventional curricula (CC), BMS are taught in distinct units (such as anatomy, microbiology, and physiology) before clinical training, while in problem-based learning (PBL) curricula, BMS are taught in the context of clinical problems and completely integrated into one PBL continuum. Most studies on attitudes of medical students towards BMS have focused on those receiving CC.

Medical students' attitudes towards BMS shape their later actions as physicians. Moreover, students' awareness on BMS research and knowledge background influences their career and choice on what to specialize on. Differences in students' approaches toward BMS have been found according to whether they receive CC or PBL curriculum (Kaufman \& Mann, 1997; West et al., 1982; D'Eon, 2006). For instance, Kaufman et al. found that students in PBL curricula adopted a more positive attitude towards BMS than students in CC (Kaufman \& Mann, 1997). Furthermore, undergraduate medical students receiving $\mathrm{CC}$ have been found to have a lower interest in BMS courses (D’Eon, 2006; Alam, 2007; Yamazaki et al., 2013; S. Gupta, A. K.Gupta, Verma, H. Kaur, A. Kaur, \& Singh, 2014). Thus Initial learning and ongoing practice have been found to contribute to this lower interest because of lack of BMS reinforcement over time (D'Eon, 2006).

A recent study indicates a decline in the basic science researches from medical journals in contrast to an increase in other forms of research by clinicians, such as epidemiology. However, the factors that could contribute to this decline in BMS research interest are still unclear (Steinberg et al., 2015). 
This cross-sectional study aimed to identify factors that affect medical students' interest towards choosing BMS or BMS research as a career.

\section{Methods}

\subsection{Participants}

This cross-sectional observational study was carried out between March and May 2016 at the College of Medicine in Riyadh, King Saud bin Abdulaziz University for Health Sciences, Saudi Arabia. Medical students participated in this study. The duration of the medical college program is 6 academic years for stream one (high school graduates) and 4 academic years for stream two (university graduates) with three sequential phases, as follows: Phase I: Premedical; Phase II: Medical; and Phase III: Clinical Clerkship.

Hard copies of the questionnaire were distributed to all (600) participants to fill out and the study's aim was explained to the students. Moreover, all participants were required to sign an informed consent form before participating. This study was approved by the Institutional Review Board in King Abdullah International Medical Research Centre (RC16/078/R).

\subsection{Questionnaire}

The questionnaire was piloted using a small number of medical students $(n=15)$ and then repeated to the same students 1 week after for reliability. Basic science educators were also requested to evaluate the questionnaire. Based on the feedback, minor changes were made to the questionnaire before distributing to the study sample, particularly with regard to multiple response answers.

All students were provided with a pre-designed self-administered questionnaire (Yamazaki et al., 2013). The 11 items questionnaire collected socio-demographic information, evaluated medical students' interest in BMS, and determined what they considered as obstacles in BMS. Questionnaire items assessed students' interest in BMS and research, whereby students responded with "very interested", "slightly interested", "not interested", and "not interested at all", and one item assessed whether students would consider becoming BMS physicians ("yes"/"no"). If students answered "no", they were asked to choose among nine possible influences on their decision, which were as follows: "I entered medical school to be a clinician", "I am not likely to be interested in BMS research", "I have never experienced an interesting lecture in BMS", "I have never experienced exciting practical training in BMS", "I have no role model", "I have no good mentors or faculty advisors", "I would prefer to engage in clinical research", and "I have concerns about the salary should I choose BMS as a career". Students were instructed to choose one or more influences, or choose "other" if they wished to indicate additional influences. Finally, students were asked whether they thought BMS faculties encourage medical students to conduct research in BMS when giving lectures.

\subsection{Statistical Analysis}

The data are presented as the mean \pm standard deviation (SD) for continuous variables and percentages for categorical variables unless otherwise stated. An independent samples t-test was used to compare continuous data. To facilitate the analysis of questionnaire data, responses under the categories "not decided yet" and "not sure" were categorized as "no". Categorical data were analyzed using Chi-square test. A p-value $<0.05$ was considered statistically significant. Data were analyzed using the IBM SPSS Statistics for Windows version 22.0 (IBMCorp, Armonk, NY, USA).

\section{Results}

A total of 352 medical students (180 male and 172 female) out of 600 responded to the questionnaire (58\%). The mean age of students was $22.14 \pm 1.82$ years (range, 19-27 years). A total of $210(59.7 \%)$ were in their pre-clinical years and $142(40.3 \%)$ were in clinical years, $225(63.9 \%)$ were interested in BMS, $308(87.5 \%)$ were interested in research, $80(22.7 \%)$ considered BMS as their future career, $127(36.1 \%)$ considered the faculty to have encouraged students to conduct research in BMS, and $148(42 \%)$ wished to receive more practical training in BMS, while only 94 (26.7\%) wished to receive more lectures.

Compared with students who reported interest in BMS, we found that students with no interest in BMS were significantly more likely to be male than female $(42.8 \%$ v. $29.1 \%, p=0.008)$, to be in their clinical years $(54.9 \% \mathrm{v}$. $23.3 \%, \mathrm{p}<0.001)$, and to not be interested in research ( $50 \%$ v. $34.1 \%, \mathrm{p}=0.040)$, and did not wish to become basic science physicians $(44.9 \%$ v. $6.3 \%, \mathrm{p}<0.001)$ (Table 1$)$. 
Table 1. Comparison of medical students' interest in basic sciences

\begin{tabular}{|c|c|c|c|c|}
\hline & $\begin{array}{l}\text { Interested } \mathrm{N} \\
(\%)\end{array}$ & $\begin{array}{l}\text { Not interested } \\
\text { N }(\%)\end{array}$ & Total & p-value \\
\hline \multicolumn{5}{|l|}{ Sex, N (\%) } \\
\hline Male & $103(57.2)$ & $77(42.8)$ & $180(51.1)$ & \multirow[t]{2}{*}{0.008} \\
\hline Female & $122(70.9)$ & $50(29.1)$ & $172(48.9)$ & \\
\hline Age, mean \pm SD y & $21.94 \pm 1.87$ & $22.21 \pm 1.8$ & $22.14 \pm 1.82$ & 0.247 \\
\hline \multicolumn{5}{|l|}{ Phase of study, N (\%) } \\
\hline Pre-clinical years & $161(76.7)$ & $49(23.3)$ & $210(59.7)$ & \multirow[t]{2}{*}{$<0.001$} \\
\hline Clinical years & $64(45.1)$ & $78(54.9)$ & $142(40.3)$ & \\
\hline Interested in research, $\mathrm{N}(\%)$ & $203(65.9)$ & $105(34.1)$ & $308(87.5)$ & 0.040 \\
\hline Have a desire to become a basic science physician, N (\%) & $75(93.8)$ & $5(6.3)$ & $80(22.7)$ & $<0.001$ \\
\hline $\begin{array}{l}\text { Basic science faculties encourage students to conduct research } \\
\text { in basic science when giving lectures, } \mathrm{N}(\%)\end{array}$ & $105(82.7)$ & $22(17.3)$ & $127(36.1)$ & $<0.001$ \\
\hline Wish to have more lectures in basic science, $\mathrm{N}(\%)$ & $79(84)$ & $15(16)$ & $94(26.7)$ & $<0.001$ \\
\hline Wish to have more practical training in basic science, $\mathrm{N}(\%)$ & $116(78.4)$ & $32(21.6)$ & $148(42)$ & 0.002 \\
\hline
\end{tabular}

Total number of participants $=352$.

In addition, students who reported interest in BMS were significantly more likely to state that basic science faculties encouraged students to conduct research in BMS (46.7\% v. $17.3 \%, \mathrm{p}<0.001)$, and wished to have more lectures $(43.4 \%$ v. $16 \%, \mathrm{p}<0.001)$ or practical sessions in BMS $(46.6 \%$ v. $21.6 \%, \mathrm{p}=0.002)$.

The major influences on not choosing BMS as a career were as follows "I entered medical school to be a clinician" (71.6\%), "I would prefer to engage in clinical research" (40.4\%), "I am concerned about the salary in BMS" (36.6\%), and "I have never experienced exciting practical training in BMS" (26.2\%).

Male students were significantly more likely to have salary concerns than female students $(56.6 \%$ v. $4.3 \%, \mathrm{p}<$ 0.001). On the other hand, compared with male students, female students more frequently reported having experienced exciting practical training in BMS $(38.6 \% \mathrm{v} .18 .6 \%, \mathrm{p}=0.003)$, the availability of good mentors $(18.6 \%$ v. $8 \%, \mathrm{p}=0.037)$, and a preference to engage in clinical research $(64.3 \%$ v. $25.7 \%, \mathrm{p}<0.001)$ (Table 2$)$.

Table 2. Between-sex comparison of influences on choosing a career as a basic science physician

\begin{tabular}{|c|c|c|c|}
\hline \multirow{3}{*}{ Influences } & \multicolumn{2}{|l|}{ Sex } & \multirow{3}{*}{ p-value } \\
\hline & Male & Female & \\
\hline & $\mathbf{N}(\%)$ & $\mathbf{N}(\%)$ & \\
\hline I entered medical school to be a clinician & $81(71.7)$ & $50(71.4)$ & 0.971 \\
\hline I am not interested in basic science or research & $25(22.1)$ & $15(21.4)$ & 0.912 \\
\hline $\begin{array}{l}\text { I have never experienced an interesting lecture in } \\
\text { basic science }\end{array}$ & $8(7.1)$ & $11(15.7)$ & 0.063 \\
\hline $\begin{array}{l}\text { I have never experienced exciting practical training in } \\
\text { basic science }\end{array}$ & $21(18.6)$ & $27(38.6)$ & 0.003 \\
\hline I have no role model & $4(3.5)$ & $8(11.4)$ & 0.061 \\
\hline I have no good mentors & $9(8)$ & $13(18.6)$ & 0.032 \\
\hline I would prefer to engage in clinical research & $29(25.7)$ & $45(64.3)$ & $<0.001$ \\
\hline I am concerned about salary in BMS career & $64(56.6)$ & $3(4.3)$ & $<0.001$ \\
\hline
\end{tabular}




\section{Discussion}

There are several reasons for the decline in popularity of basic sciences (Steinberg et al., 2015). Here, we sought to identify demographic factors that influence attitudes towards BMS and obstacles perceived by students. Furthermore, this is the first study in Saudi Arabia to explore medical students' interest in basic sciences. A variety of factors inspired Saudi medical students to choose basic science as a future medical specialty. Namely, we found that students interested in basic sciences were significantly more likely to report efforts made by the basic science faculty to encourage students to conduct basic science research, and more interested to receive more lectures or practical sessions in basic sciences. Therefore, faculty members should discuss their own research interests with students and use research findings as a part of their teaching material; we believe that this would increase students' awareness of the importance of basic science.

We expected stream two students to show more interest in basic sciences; while there was a difference between stream one and two students as indicated in the method participants section, this was not significant. Thus, interest in BMS might have been influenced by demographic characteristics or a strong background in science.

The retention of basic science knowledge has been found to be significantly influenced by the year of study, sex, and student origin (Malau-Aduli et al., 2013). Other studies proposed that parental, teacher, and personal interest factors affect students perception towards science (Ezeweani \& Atomatofa, 2012). Our finding also supported the significant role of teachers in determining students interest in BMS by putting theory into practice and determine whether a student can have positive interest in the subject or not.

We found that salary concerns were one of the main obstacles to pursuing basic science, especially among male students. This is consistent with findings that medical students worry about the salary difference between a career in BMS and as clinicians as they are concerned they will be paid less in BMS (Patel, Katz, \& Volpp, 2010; Olson et al., 2011; Taniguchi \& Suzuki, 2007).

This study has some limitations that should be noted. First, as with any self-report questionnaire, it is possible that there was reporting bias (Althubaiti, 2016). Second, this was a single center study with a low response rate; therefore, the generalizability of the current findings is negatively affected. However, this study nonetheless provides strong initial data concerning the characteristics of students interested in careers in basic sciences.

In conclusion, our results suggest that integrating basic science into clinical medicine, as well as increasing participation in research, increases students' positive attitudes towards basic science. Moreover, reducing the identified concerns will encourage medical students to engage in BMS. For instance, improving the financial status plan for BMS careers and increasing research grants could reduce the financial obstacles students face. Furthermore, the present results will aid student mentors and directors of residency training programs to encourage students to choose specialties that receive less interest than the others in Saudi Arabia.

\section{Competing Interests Statement}

The authors declare that there are no competing or potential conflicts of interest regarding the publication of the paper.

\section{References}

Alam, A. (2007). How do medical students in their clinical years perceive basic sciences courses at King Saud University? Ann Saudi Med., 31(1), 58-61. https://doi.org/10.4103/0256-4947.75780

Althubaiti, A. (2016). Information bias in health research: definition, pitfalls, and adjustment methods. $J$ Multidiscip Healthc, 9, 211-217. https://doi.org/10.2147/JMDH.S104807

Dahle, L. O., Brynhildsen, J., Behrbohm Fallsberg, M., Rundquist, I., \& Hammar, M. (2002). Pros and cons of vertical integration between clinical medicine and basic science within a problem-based undergraduate medical curriculum: examples and experiences from Linköping, Sweden. Med Teach., 24(3), 280-285. https://doi.org/10.1080/01421590220134097

D'Eon, M. F. (2006). Knowledge loss of medical students on first year basic science courses at the University of Saskatchewan. BMC Med Educ., 6, 5. https://doi.org/10.1186/1472-6920-6-5

Ezeweani, U. L., \& Atomatofa, R. O. (2012). Choosing a career in science: The Nigerian student perception. International Journal of Research Studies in Educational Technology, 1(2), 73-81. https://doi.org/10.5861/ijrset.2012.201

Gupta, S., Gupta, A. K., Verma, M., Kaur, H., Kaur, A, \& Singh, K. (2014). The attitudes and perceptions of medical students towards basic science subjects during their clinical years: A cross-sectional survey. Int $J$ 
Appl Basic Med Res., 4(1), 16-19. https://doi.org/10.4103/2229-516X.125675

Kaufman, D. M., \& Mann, K. V. (1997). Basic sciences in problem-based learning and conventional curricula: students' attitudes. Med Educ., 31(3), 177-180. https://doi.org/10.1111/j.1365-2923.1997.tb02562.x

Kaufman, D. M., \& Mann, K. V. (1996). Comparing students' attitudes in problem-based and conventional curricula. Academic Medicine, 71(10), 1096-1099. https://doi.org/10.1097/00001888-199610000-00018

Malau-Aduli, B., Lee, A., Cooling, N., Catchpole, M., Jose, M., \& Turner, R. (2013). Retention of knowledge and perceived relevance of basic sciences in an integrated case-based learning (CBL) curriculum. BMC Med Educ., 13, 139. https://doi.org/10.1186/1472-6920-13-139

Olson, D. P., Oatts, J. T., Fields, B. G., \& Huot, S. J. (2011). The residency application abyss: insights and advice. Yale J. Biol. Med., 84, 195-202.

Patel, V. L., Evans, D. A., \& Groen, G. J. (1989). Biomedical knowledge and clinical reasoning. Cognitive science in medicine: Biomedical modeling. Cambridge MAT, 1989.

Patel, V. L., Evans, D. A., \& Kaufman, D. R. (1990). Reasoning strategies and the use of biomedical knowledge by medical students. Med Educ., 24(2), 129-136. https://doi.org/10.1111/j.1365-2923.1990.tb02511.x

Patel, M. S., Katz, J. T., \& Volpp, K. G. (2010). Match rates into higher-income, controllable lifestyle specialties for students from highly ranked, research-based medical schools compared with other applicants. J. Grad. Med. Educ., 2, 360-365. https://doi.org/10.4300/JGME-D-10-00047.1

Steinberg, B. E., Goldenberg, N. M., Fairn, G. D., Kuebler, W. M., Slutsky, A. S., \& Lee, W. L. (2015). Is basic science disappearing from medicine? The decline of biomedical research in the medical literature. The FASEB Journal, 30(2), 515. https://doi.org/10.1096/fj.15-281758

Taniguchi, N., \& Suzuki, K. (2007) Results of a questionnaire survey conducted by the Council on Medical Biochemistry and Molecular Biology Education and the Japanese Biochemical Society regarding the crisis in medical education and research in basic science. Seikagaku, 79, 98-104 (in Japanese).

West, M., Mennin, S. P., Kaufman, A., \& Galey, W. (1982). Medical students' attitudes toward basic sciences: influence of a primary care curriculum. Med Educ., 16(4), 188-191. https://doi.org/10.1111/j.1365-2923.1982.tb01246.x

Yamazaki, Y., Uka, T., Shimizu, H., Miyahira, A., Sakai, T., \& Marui, E. (2013). Japanese medical students' interest in basic sciences: a questionnaire survey of a medical school in Japan. Tohoku J Exp Med., 229(2), 129-136. https://doi.org/10.1620/tjem.229.129

\section{Copyrights}

Copyright for this article is retained by the author(s), with first publication rights granted to the journal.

This is an open-access article distributed under the terms and conditions of the Creative Commons Attribution license (http://creativecommons.org/licenses/by/4.0/). 